\title{
Debt Dynamics and Monetary Policy: A Note*
}

\author{
Stefan Laséen ${ }^{\dagger} \quad$ Ingvar Strid ${ }^{\ddagger}$ \\ Sveriges Riksbank Working Paper Series \\ No. 283 \\ December 2013
}

\begin{abstract}
"Leaning against the wind" - a tighter monetary policy than necessary for stabilizing inflation around the inflation target and unemployment around a long-run sustainable rate has been justified as a way of reducing household indebtedness. In a recent paper Lars Svensson claims that this policy is counterproductive, since a higher policy rate actually leads to an increase (and not a decrease) in real debt and the debt-to-GDP ratio. In this note we offer some comments and extensions to Svensson's analysis. In particular, we take Svensson's debt model to the data and show that it provides an incomplete account of short term debt dynamics. Further, the overall analysis of the effects of monetary policy on debt rests on the rather strong assumption that debt is independent of the policy rate, conditional on housing prices. The policy responses advocated by Svensson can therefore be questioned. More importantly, our exercises with a modified model of debt dynamics enables further understanding of how different assumptions affect the assessment of the effects of monetary policy on debt.
\end{abstract}

JEL Classification: C32, E21, E31, E32, E44, E52, R21, R31.

Keywords: House prices, Mortgage Debt, Monetary policy, Bayesian Estimation, Structural VAR.

\footnotetext{
${ }^{*}$ We are grateful to Eric Frohm, Ulf Söderström, Karl Walentin and participants at the Riksbank Seminar Series, and, in particular, Lars E.O. Svensson for helpful comments and discussions. The views, analysis, and conclusions expressed in this paper are solely the responsibility of the authors and should not be interpreted as reflecting the views of the Executive Board of Sveriges Riksbank.

${ }^{\dagger}$ Sveriges Riksbank, SE-103 37, Stockholm, Sweden. e-mail: stefan.laseen@riksbank.se.

${ }^{\ddagger}$ Sveriges Riksbank, SE-103 37, Stockholm, Sweden. e-mail: ingvar.strid@riksbank.se.
} 


\section{Contents}

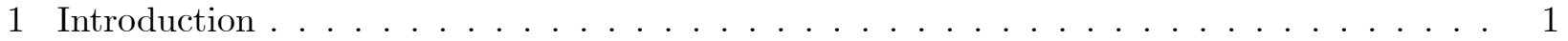

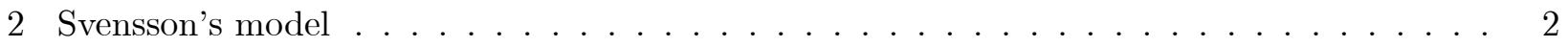

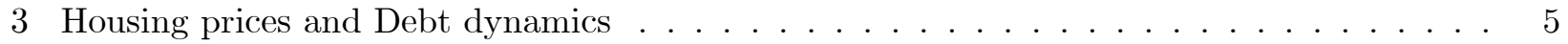

3.1 Lars Svensson's setup and calibration: constant house price growth . . . . . . . . . 5

3.2 Simulating the evolution of debt using the model and actual Swedish house prices . . 6

4 Debt dynamics and monetary policy . . . . . . . . . . . . . . . . . . 10

4.1 The effects of monetary policy on real debt and the debt-to-GDP ratio in Svensson

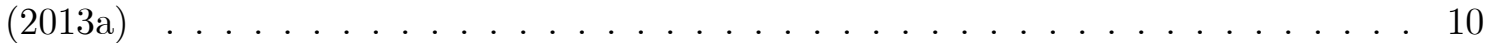

4.2 A VAR model with house prices and debt: the effects of a monetary policy shock . . 11

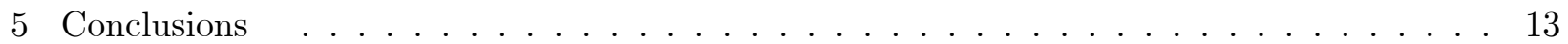

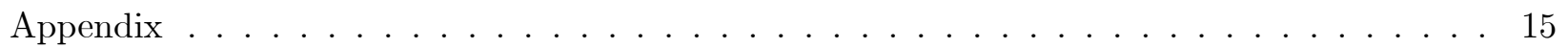

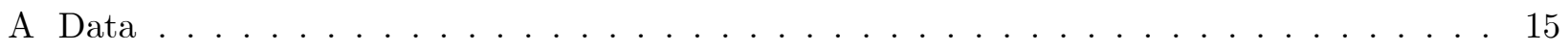

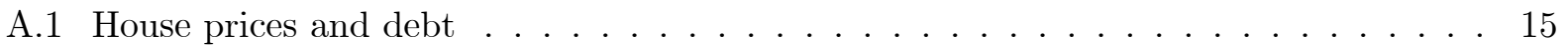

A.2 LTV-ratios on new loans, average LTV-ratios and a measure of the turnover rate of

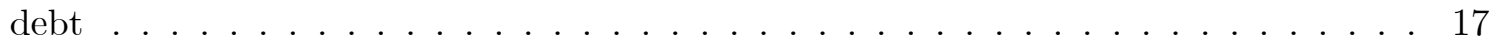

A.3 Other data series . . . . . . . . . . . . . . . . . . . . . 17

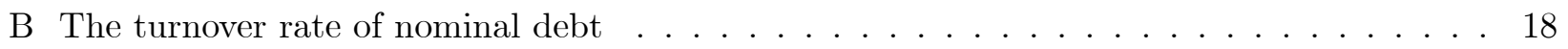

C The BVAR model . . . . . . . . . . . . . . . . . . . . . . 19

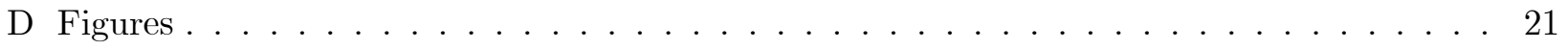




\section{Introduction}

In a recent paper, Lars Svensson [9] presents a simple and intuitive model of (mortgage) debt dynamics. The main feature of the model is that a relatively small share of the total mortgage stock is turned over each year. New mortgages are assumed to arise from purchases of new housing, but new loans may also be due to refinancing by housing owners who are not moving to a new house. Given plausible assumptions on the effects of a monetary policy shock on inflation and GDP, Svensson shows that the effects of exogenous interest rate changes feed through the stock of debt so slowly that real debt (i.e. nominal debt deflated by a price index), and the debt-to-GDP ratio, actually increase (and not decrease) following a policy shock which increases the interest rate. Hence, "Leaning against the wind" - a tighter monetary policy than necessary for stabilizing inflation around the inflation target and unemployment around a long-run sustainable rate - can not be justified as a way of reducing household indebtedness.

In this note, we focus on the relation between the shorter-term dynamics of debt and the effects of monetary policy on debt. We first establish that a slightly modified version of Svensson's model can, in fact, reproduce some features of actual debt series quite accurately. However, in order to better match the evolution of actual debt (here Swedish debt in the past 15 - 30 years) with the model, a shorter refinancing period of mortgages is required, in comparison with what Svensson assumes. This suggests that the model fails to capture some important factors accounting for shortterm fluctuations in debt, e.g. time variation in loan-to-value (LTV) ratios, or that the dynamics of housing equity withdrawals are not accurately described. This shortcoming of the model is mainly manifested through a too persistent growth rate of debt in the model. We conclude that Svensson's model provides an incomplete account of short term debt dynamics.

Svensson's calculation of the effects of monetary policy on debt further (implicitly) assumes that the effects of monetary policy on debt works only through its effect on housing prices. In statistical language, Svensson assumes that debt is independent of the repo rate (as well as other macroeconomic variables) conditional on housing prices. The inability of the debt model to account for the short-run fluctuations in debt is related to this, rather strong, prior belief. As a consequence we argue that Svensson's suggested responses of real debt and the debt-to-GDP ratio to an exogenous change in the repo rate can be questioned.

In order to provide further understanding of how different assumptions affect the assessment of the effects of monetary policy on debt we then return to the standard framework for studying 
such issues. The effects of monetary policy shocks on real and nominal debt are estimated using a Bayesian structural (i.e. identified) vector autoregressive (BVAR) model. A positive monetary policy shock, which increases the repo rate, leads to a (temporary) decrease in GDP, a decrease in inflation and a decrease in real housing prices. Further, both real household debt and the debtto-GDP ratio fall in response to the positive policy shock. The signs of these two responses are therefore opposite to the signs implied by Svensson's analysis. In order to understand the differences we proceed by replacing the actual debt data series in the BVAR with a counterfactual debt series, which is generated using Svensson's debt model and Svensson's calibration of the model. Replacing actual data on debt with the counterfactual debt series we are able to recover Svensson's signs of the real debt and debt-to-GDP responses. However, the properties of the debt series needed to generate these effects do not match the properties of Swedish debt data.

Our results suggest that it is important to further understand the short run dynamics of mortgage debt, in order to enable a better understanding of the effects of monetary policy on real and nominal debt. In particular it appears important to understand how, and to what extent, monetary policy affects the flow of (mortgage) loans which are not directly related to housing transactions, and the impact of policy on the LTV-ratios chosen by households. The implications concerning the more general issue - the appropriateness of the "Leaning against the wind" policy - remains an open question.

This paper is outlined as follows; in section 2 we present Svensson's model with three trivial extensions, in section 3, we simulate the path of debt, given a sequence of house prices, to evaluate whether Svensson's model match actual (Swedish) data on household debt, in section 4 we attempt to better understand the qualitative (i.e. sign) response of real debt and the debt-to-GDP ratio to a monetary policy shock. In order to do this we take Svensson's model to the standard framework for the identification of the effects of monetary policy shocks. Finally, section 5 concludes.

\section{Svensson's model}

Svensson presents a simple and straightforward model of (mortgage) debt dynamics (Svensson [9]). We make three trivial extensions to Svensson's model, with the sole purpose of taking the model to the data. First, house price growth, which is exogenous, is allowed to be time-varying (rather than constant). This allows us to compute model-based time series for debt, the LTV for new mortgages and the average LTV ratio, given an arbitrary sequence of house prices, e.g. a time series of actual house prices. Second, the LTV for new mortgages is allowed to be time-varying 
(rather than constant). This allows us to compute a model-based time series for this variable, given arbitrary sequences of house prices and debt. Third, we define the time period to be one quarter instead of one year as in Svensson, since data on house prices and debt are available at a quarterly frequency.

Let $P_{t}$ denote the nominal price of housing in (the beginning of) period (i.e. quarter) $t$. Further, let $H_{t}$ denote the housing stock in period $t$, such that

$$
V_{t}=P_{t} H_{t}
$$

is the nominal value of the housing stock in period $t$. Assume that house owners keep their housing for a holding period of $T_{h}$ periods, and that each period a fraction $1 / T_{h}$ of the housing stock is turned over. If the housing stock is constant, as Svensson assumes, then $H_{t}=H / T_{h}$ of the housing stock is turned over in each period. Further, assume that housing owners amortise at the rate $0 \leq \beta<1$, i.e. a (constant) fraction $\beta$ of the remaining mortgage is repaid in each period. The remaining amount in period $t+s$ of a mortgage $m_{t}$, issued in period $t$, is thus $m_{t}(1-\beta)^{s}$. The remaining mortgage at the end of the housing holding period, i.e. after $T$ periods, is repaid when the housing is sold.

Let $m_{s}$ denote the nominal value of the new mortgage loans issued in period $s$. Assume that the average LTV ratio of new mortgage loans in period $s$ is given by $\alpha_{s}$ (i.e. it is the average across all new mortgages in that period). In order to interpret Svensson's calibration of the model we find it useful to assume that the flow of new mortgages, $m_{s}$, consists of two components: (i) mortgages which are directly related to housing transactions, $m_{s}^{h}$, and (ii) a residual component capturing mortgage loans which are not directly related to housing transactions, $m_{s}^{r}$, such that

$$
m_{s}=m_{s}^{h}+m_{s}^{r}, \text { where } m_{s}^{r} \geq 0
$$

Now, Svensson assumes that the nominal value of new mortgages is given by

$$
m_{s}=\alpha_{s} \frac{V_{s}}{T}
$$

where $1 / T$ is the fraction of mortgages which are refinanced. Further, assume that the component of new mortgage loans which is directly related to housing transactions is determined analogously as

$$
m_{h}=\alpha_{s} \frac{V_{s}}{T_{h}}, \text { where } T \leq T_{h}
$$


Combining 2.3 and 2.4 we obtain a relationship between the mortgage loan holding period, $T$, the housing holding period, $T_{h}$, and the share of new mortgage loans (of the total) which are directly associated with housing transactions, $m_{s}^{h} / m_{s}$, given by

$$
\frac{m_{s}^{h}}{m_{s}}=\frac{T}{T_{h}}
$$

Further, the residual mortgages are given by

$$
m_{s}^{r}=m_{s}\left(1-\frac{T}{T_{h}}\right)
$$

Note again that the expressions 2.2, 2.4, 2.5 and 2.6 are merely included to be able to interpret Svensson's calibration of the refinancing period, $T$.

The debt stock in period $t$ consists of the mortgages issued over the past $T$ periods, with amortisations subtracted,

$$
D_{t}=\sum_{s=0}^{T-1} m_{t-s}(1-\beta)^{s}=\sum_{s=0}^{T-1} \alpha_{t-s} \frac{V_{t-s}}{T}(1-\beta)^{s} .
$$

With a constant housing stock normalised to unity, $H_{t}=1$ ( $\operatorname{such}$ that 2.1 reduces to $V_{t}=P_{t}$ ), a constant LTV ratio for new mortgages, $\alpha_{s}=\alpha$, and no amortisation, $\beta=0$, this expression simplifies to

$$
D_{t}=\frac{\alpha}{T} \sum_{s=0}^{T-1} P_{t-s}
$$

The average LTV-ratio, that is the LTV ratio of all outstanding mortgage loans, is given by

$$
A_{t}=\frac{D_{t}}{V_{t}}
$$

The turnover rate of (nominal) debt may be defined as

$$
\gamma_{t}^{d}=\frac{m_{t}}{D_{t}}=\frac{\alpha_{t} \frac{V_{t}}{T}}{\sum_{s=0}^{T-1} \alpha_{t-s} \frac{V_{t-s}}{T}(1-\beta)^{s}} .
$$

It is instructive to briefly consider two sets of simplifying assumptions and their implications for the turnover rate of debt. First, assuming constant house prices, $g=0$, a constant LTV for new mortgages, $\alpha_{t}=\alpha$ and no amortisations, $\beta=0$, the debt stock is constant, $D=\alpha P$, and the turnover rate of debt equals the fraction of mortgages which are refinanced, $1 / T$. Second, assuming constant house price growth, $g_{t}=g>0,{ }^{1}$ along with $\alpha_{t}=\alpha$ and $\beta=0$, the turnover rate of debt

\footnotetext{
${ }^{1}$ In the case where nominal house prices $P_{t}$ grow with a constant nominal growth rate, $g$, they satisfy $P_{t}=$ $P_{0}(1+g)^{t}$.
} 
equals

$$
\gamma^{d}=\frac{g}{1+g-(1+g)^{-T+1}}\left(\rightarrow \frac{1}{T} \text { as } g \rightarrow^{+} 0\right) .
$$

The turnover of the stock of debt is thus determined by the mortgage holding period, $T$, and house price growth, $g_{t}$. This is a key assumption in Svensson [9] and an assumption we will get back to in the following sections. Furthermore, in the case of constant house price growth, the average LTV-ratio, $A_{t}=A$, the LTV-ratio on new mortgages, $\alpha_{t}=\alpha$, and the turnover rate of debt, $\gamma_{t}^{d}=\gamma^{d}$, are related through

$$
\gamma^{d}=\frac{\alpha}{A T}
$$

Derivations of expressions [2.11] and [2.12] are provided in the appendix.

The model outlined above is a model of debt, conditional on (exogenously given) house prices, which may be expressed through the density

$$
P\left(D_{0: T^{*}} \mid P_{0: T^{*}}, \alpha_{0: T^{*}}, H_{0: T^{*}} ; \theta\right),
$$

where the vector of parameters, $\theta$, is given by $\theta=(\beta, T) .^{2}$ For given sequences of housing prices $P_{0: T^{*}}=\left\{P_{t}\right\}_{t=0}^{T^{*}}$ (where $T^{*}$ denotes the end of the sequence or time series and should not be confused with the holding period of housing, $T$ ), the housing stock $\left\{H_{t}\right\}_{t=0}^{T^{*}}$, the LTV ratio for new mortgages, $\left\{\alpha_{t}\right\}_{t=0}^{T^{*}}$, and the constant rate of amortisation, $\beta$, it is straightforward to compute the sequence of debt $\left\{D_{t}\right\}_{t=0}^{T^{*}}$, the sequence of average LTV-ratios $\left\{A_{t}\right\}_{t=0}^{T^{*}}$, and the sequence of turnover rates of debt $\left\{\gamma_{t}^{d}\right\}_{t=0}^{T^{*}}$. On the other hand, given sequences of housing prices and debt, it is possible to solve for the sequence of LTV ratios for new mortgages, $\left\{\alpha_{t}\right\}_{t=0}^{T^{*}}$. From an implementation perspective, allowing $\alpha_{t}$ and $g_{t}$ to be time-varying, rather than constant, means that some results for geometric series which are applied by Svensson can no longer be used.

\section{Housing prices and Debt dynamics}

\subsection{Lars Svensson's setup and calibration: constant house price growth}

We begin by reproducing the steady-state baseline used in Svensson [9]. Assume a constant LTVratio on new mortgages, $\alpha_{t}=\alpha=70 \%$, and a mortgage refinancing period of 7 years, which corresponds to $T=4 \times 7=28$ quarters. The interpretation of the model clearly depends on how it is calibrated. In an earlier version of Svensson's paper the mortgage refinancing period

\footnotetext{
${ }^{2}$ The vectors $\alpha_{0: T^{*}}$ and $H_{0: T^{*}}$ are treated as parameters in the analysis here. Further, note that conditional on the parameters the density collapses to a deterministic relation between house prices and debt. In other words, there is no stochastic element in the model presented here.
} 
was calibrated to $T=T_{h}=60$ quarters, in order to match the average housing holding period in Sweden (which is between 15 and 18 years). Our interpretation of the previous calibration, where $T=T_{h}$, is that in this case it is assumed that all new mortgage loans are associated with housing transactions, see expression 2.5. ${ }^{3}$ With our interpretation of the model (see expressions 2.2, 2.4, 2.5 and 2.6) and Svensson's current calibration, the approximate fraction of mortgage loans associated with housing transactions instead equals

$$
\frac{m_{s}^{h}}{m_{s}}=\frac{T}{T_{h}}=\frac{7}{15}
$$

i.e. roughly half of the mortgage loans are directly related to housing transactions. Finally, assume that housing prices grow by $4 \%$, which corresponds to a quarterly growth rate of $g_{t}=g=0.985 \%$. In Figure 1 the nominal housing prices, debt and the average LTV ratio are displayed. The turnover rate of debt equals $16 \%$ in annual terms, i.e. in each quarter the flow of new mortgage debt constitutes a fraction $4 \%$ of the (end of period) debt stock.

\subsection{Simulating the evolution of debt using the model and actual Swedish house prices}

Svensson shows how total debt and the average LTV ratio responds to a change in housing prices. In particular, housing prices are assumed to increase by $1 \%$ (relative to the baseline) in year 1 and then return back to the baseline in year 2. As a consequence total debt increases by $0.16 \%$ in year 1, before it falls back slowly to the baseline path. The calculation of the effect on nominal debt in the first year (the percentage change at a yearly frequency) is given by

$$
\Delta \log D=(\Delta \log P) \gamma^{d}=(\Delta \log P) \frac{\alpha}{A} \frac{1}{T}=1 \times \frac{70}{62} \times \frac{1}{7}=0.161 \%
$$

Note that the effect on debt equals the turnover rate of debt, as defined above.

A natural extension of this experiment is to simulate the path of debt given a sequence of house prices, and to evaluate if Svensson's calibration match actual data on household debt. Essentially this means that the calculation in (3.1) is repeatedly applied for a time series of house prices. Here quarterly data on Swedish house prices for the period 1995Q1-2013Q2 are used (replacing the constant growth rate assumption), while all other assumptions are kept as above. For this time period the average yearly growth in housing prices is roughly $6 \%$. In Figure 2 housing prices, debt

\footnotetext{
${ }^{3}$ In the first version of Svensson's article $T$ was defined to be the housing holding period, i.e. $T=T_{h}$, while in the most recent version it is defined to be the mortgage holding period, and therefore $T<T_{h}$.
} 
and the LTV-ratio are displayed along with the model-implied debt and LTV series. ${ }^{4}$ The modelsimulated debt series lies below the actual debt series, e.g. in 2013 it is roughly $12 \%$ below the actual level. The higher average growth rate in the observed house prices, compared with Svensson's assumed growth rate of $4 \%$, also results in a simulated LTV ratio which is too low. However, even though Svensson did not calibrate the model to fit the historical debt data the overall trend in the data is captured reasonably well. The model implied debt growth, on the other hand, is much more persistent and less volatile than in the actual data.

In the lower-right panel of Figure 2 the model-implied turnover rate of debt is compared with a data-based measure of this quantity. It is seen that the model-implied turnover rate matches the data at the end of the sample period, which motivates the calibration $T=28 .{ }^{5}$ Our measure of the turnover rate of debt has been computed based on data on the volume of new mortgage loans and the stock of mortgage loans for the period 2009Q1-2012Q3. The data on the SEK volume of new loans is obtained from Finansinspektionen, [4] and [5], and the stock of mortgage loans is obtained from the SCB Financial Market Statistics, [13]. Further details on the calculations are provided in the data appendix.

In order to obtain a better data fit for debt we proceed in two steps. First, the LTV on new mortgage loans, $\alpha_{t}=\alpha$, and the initial value of the average LTV ratio, $A_{0}$ (where $t=0$ corresponds to 1994Q4), are calibrated to capture some features of the corresponding data series reasonably accurately. The LTV for new mortgage loans has increased from 59\% in 2002 to $69 \%$ in 2013 (Finansinspektionen, [4] and [5]). Based on these numbers we let $\alpha_{t}=\alpha=65 \%$. The average LTV on mortgage debt was 63\%,60\% and 65\% in 2009, 2011 and 2012 (Finansinspektionen, [4] and $[5])^{6}$. To broadly match these features of the data we select $A_{0}=A_{1994 Q 4}=58 \%$. Second, given the calibration of $\alpha$ and $A_{0}$, the refinancing period, $T$, is selected to minimise the distance between the model-implied debt series and the actual debt series. Let $\left\{D_{t}\right\}_{t=0}^{T^{*}}$ denote the actual debt time series, and let $\left\{D_{t}^{m}\right\}_{t=0}^{T^{*}}$ be the model-implied time series. Hence the following problem is solved:

$$
\min _{T} \sum_{t=0}^{T^{*}}\left(D_{t}-D_{t}^{m}\right)^{2},
$$

and the solution is the value of $T$ which yields the best correspondence between model-implied debt

\footnotetext{
${ }^{4}$ The actual debt series used here is the total household financial debt. See the appendix for further discussion of available measures of debt.

${ }^{5}$ The old calibration $T=T_{h}=60$ quarters instead implies that the turnover rate of debt is too low.

${ }^{6}$ Note that the average LTV for mortgage loans which are included in Swedish bank's cover pools is lower than the numbers presented here. For the major Swedish banks the average LTV on mortgage loans included in cover pools in 2012 range from $47 \%$ (Handelsbanken) to 59\% (SE-banken). The LTV-ratio on a loan included in a cover pool may not exceed $75 \%$. This explains why the cover pool LTV-ratios are lower than the LTV-ratio published by Finansinspektionen.
} 
and the actual debt series.

It turns out that in order to better capture the dynamics of debt in the data we need a fairly short refinancing period, $T$. The best fit is obtained with $T=15$, i.e. 3.75 years. Remember that Svensson use $T=28$ (i.e. 7 years) as a reasonable assumption for the refinancing period. In Figure 3 it is seen that the model-implied debt series match the debt trend and the low frequency component of debt growth quite accurately. However, the model still cannot account for the highfrequency movements in the debt growth rate. In table 1 results from further optimisations are presented, where the sample period and the criterion variable are altered. These results show more generally that the best fit of debt, or debt growth, is obtained with a fairly 'small' value of $T$ (relative to Svensson's calibration).

Table 1 Results from optimisations of (3.2).

\begin{tabular}{lllc}
\hline \hline Fit & Sample & $\alpha$ & Optimal T \\
\hline \hline Debt level & 1995Q1-2013Q2 & 0.65 & 15 \\
Debt level & 1986Q2-2013Q2 & 0.65 & 8 \\
Quarterly debt growth & 1995Q1-2013Q2 & 0.65 & 24 \\
Quarterly debt growth & 1986Q2-2013Q2 & 0.65 & 9 \\
\hline \hline
\end{tabular}

In table 2 some time series properties of debt and the model-implied debt series produced in the experiments above are collected. We note that Svensson's calibration yields a much more persistent, and less volatile, debt growth series in comparison with the data. In the case of the 'optimal' calibration, the volatility of debt growth is roughly in line with the data, while the firstorder autocorrelation is still too large. In order to further understand how the properties of debt depend on $T$ we also include the case of an 'extreme' calibration, where the stock of debt is assumed to be turned over once a year, $T=4$. The numbers obtained imply that it is not possible to match the persistence properties of debt growth in the data simply by varying $T$.

Table 2 Properties of model-generated debt growth series, 1995Q1-2013Q2.

\begin{tabular}{lllll} 
& $\alpha$ & $T$ & $s t d\left(\Delta \log D_{t}\right)$ & $\operatorname{corr}\left(\Delta \log D_{t}, \Delta \log D_{t-1}\right)$ \\
\hline \hline Svensson's original calibration & 0.70 & 60 & 0.33 & 0.99 \\
Svensson's calibration & 0.70 & 28 & 0.49 & 0.99 \\
'Optimal' calibration & 0.65 & 15 & 0.60 & 0.96 \\
'Extreme' calibration & 0.65 & 4 & 1.11 & 0.85 \\
Household total financial debt (data) & - & - & 0.72 & 0.80 \\
Mortgage debt (data) & - & - & 1.03 & 0.64 \\
\hline \hline
\end{tabular}


In the experiments so far the LTV-ratio for new mortgages has been kept constant, i.e. $\alpha_{t}=\alpha$. In order to better capture the dynamics of debt, within this framework, one possibility is to allow for time variation in the LTV-ratio. Here we evaluate the fit of the model by first solving for the sequence of LTV-ratios on new mortgages, and then comparing it with a measure of LTV on new loans in the data. We feed both the house price series and the debt series through equation (2.8) and compute the implied sequence of LTV-ratios for new mortgages, $\left\{\alpha_{t}\right\}_{t=0}^{T^{*}}$. (Note that the average LTV of all loans will be 'perfectly matched' in this case since it is simply the ratio between house prices and debt, by assumption). This sequence will depend both on the house price and debt data, and the calibration of $T$ and $A_{0}$. The model series may be compared, at least casually, with yearly data on the LTV-ratio on new mortgage loans (Finansinspektionen, [4] and [5]). The model-implied LTV series with Svensson's calibration $\left(T=28, A_{0}=62 \%\right)$ is displayed in Figure 4. The implied LTV series does not seem to be consistent with the data, e.g. the volatility of the LTV-ratio appears too large in comparison with the data. This is just another, complementary, way of illustrating the missing debt dynamics in Svensson's calibration.

The LTV series with the 'optimal' calibration $\left(T=15, A_{0}=58 \%\right)$ is displayed in Figure 5 . Again, fairly large fluctuations in $\left\{\alpha_{t}\right\}_{t=0}^{T^{*}}$ are needed in order to replicate the debt growth series in the data. However, it appears that with this calibration of the model, at least the approximate level of the LTV-ratio and the upward trend on new loans between 2002 and 2012 can be captured reasonably well.

The experiments above show that Svensson's model, with actual housing prices as the exogenous driver, is able to reproduce the time series properties of debt reasonably accurately. We conclude this section with two remarks. First, mortgage debt is not merely created when housing is bought or sold, i.e. a reasonable value of the refinancing period, $T$, is substantially lower than a reasonable value for the housing holding period, $T_{h}$. Svensson's recalibration (and therefore reinterpretation) of the model, from $T=T_{h}=60$ to $T=28<T_{h}$, addresses this issue. However, we show that in order to reproduce the actual debt time series one needs to assume a refinancing period of debt, $T$, which is even lower than 7 years. Second, given that the model is calibrated with $T \ll T_{h}$ (which means that there exist mortgage loans which are not directly related to housing transactions) it is not obvious that housing-related mortgages, $m^{h}$, and residual mortgages, $m^{r}$, should be modelled in the same way, see 2.4 and 2.6. Further, in order to capture the high frequency movements in the debt growth rate, one possibility within the current modeling framework is to allow for time variation in the LTV-ratio on new mortgages. 


\section{Debt dynamics and monetary policy}

In this section we attempt to better understand the qualitative (i.e. sign) response of real debt and the debt-to-GDP ratio to a monetary policy shock. First we briefly review Svensson's calculation of these effects. Then we take Svensson's debt model to the standard framework for the identification of the effects of monetary policy shocks. The question we posit is the following: applying the standard tools, which assumptions are needed in order to reproduce the results of Svensson (i.e. that real debt and the debt-to-GDP ratio increase following a positive monetary policy shock)?

\subsection{The effects of monetary policy on real debt and the debt-to-GDP ratio in Svensson} (2013a)

Svensson computes the effects of monetary policy on real debt and the debt-to-GDP ratio through three separate calculations. First, the effect on housing prices of an exogenous change in the repo rate is computed based on the user cost approach (Svensson [10]). Our estimate of this effect is quite similar to Svensson's and therefore it is not considered further here. Second, the effect of a change in housing prices on nominal debt is computed using the debt model outlined above, see in particular expression 3.1 where the calculation of the first year effect on debt of a change in housing prices is provided. (In section 3 we illustrated how repeated application of Svensson's calculation of the effect of housing prices on debt yielded a debt time series which is too persistent in comparison with actual data.) Finally, the response of nominal debt is combined with the policy responses of CPIF inflation and GDP, to obtain the responses of real debt and the debt-to-GDP ratio, respectively. The responses of CPIF inflation and GDP are assumed to be equal to the responses in the Riksbank's main macroeconomic model, Ramses (Adolfsson, et. al. [1]).

On an abstract level one may think of Svensson's computations through a model (i.e. a joint probability density function for a sequence of variables), $\tilde{P}$, containing house prices, $P$, nominal debt, $D$, the repo rate, $i$, and a vector of macroeconomic variables, $X$, which include e.g. CPIF inflation and GDP. The density $\tilde{P}$ may be factorised into conditional densities,

$$
\begin{gathered}
\tilde{P}\left(D_{0: T^{*}}, P_{0: T^{*}}, i_{0: T^{*}}, X_{0: T^{*}}\right)= \\
=\tilde{P}_{1}\left(D_{0: T^{*}} \mid P_{0: T^{*}}, i_{0: T^{*}}, X_{0: T^{*}}\right) \tilde{P}_{2}\left(P_{0: T^{*}} \mid i_{0: T^{*}}, X_{0: T^{*}}\right) \tilde{P}_{3}\left(i_{0: T^{*}}, X_{0: T^{*}}\right),
\end{gathered}
$$

where each conditional density, or 'submodel', match a particular calculation by Svensson, i.e. the debt model is captured by $\tilde{P}_{1}$, the user cost approach to housing prices is captured by $\tilde{P}_{2}$, and the model of the standard macroeconomic variables, in this case Ramses, is captured by $\tilde{P}_{3}$. 
The submodel for debt is, further, assumed to be of the form

$$
\tilde{P}_{1}\left(D_{0: T^{*}} \mid P_{0: T^{*}}, i_{0: T^{*}}, X_{0: T^{*}}\right)=\tilde{P}_{1}\left(D_{0: T^{*}} \mid P_{0: T^{*}}\right),
$$

e.g. nominal debt and the repo rate are independent, conditional on housing prices. In this context, the failure of the debt model to account for the short-term fluctuations in debt growth may be thought of as an 'omitted variable problem'. For example, an obvious 'omitted variable' candidate (since it is already included in the debt model while assumed to be constant) is the LTV-ratio on new loans, $\alpha_{t}$. However, allowing $\alpha_{t}$ to be time-varying in the debt model would necessitate an assessment of the effects of monetary policy on the LTV-ratio of new loans. This potential channel of monetary policy is obviously not included in Svensson's calculations.

\subsection{A VAR model with house prices and debt: the effects of a monetary policy shock}

A common way to estimate the effects of a monetary policy shock on economic variables is to use a (possibly Bayesian) structural (i.e. identified) vector autoregressive (BVAR) model. The baseline BVAR model applied here contains quarterly data for the following eight variables: trade-weighted measures of foreign GDP in $\operatorname{logs}\left(y_{t}^{f}\right)$, CPIF inflation $\left(\pi_{t}^{f}\right)$ and a short-term interest rate $\left(i_{t}^{f}\right)$, the corresponding domestic variables $\left(y_{t}, \pi_{t}\right.$, and $\left.i_{t}\right)$, the log of real debt (household nominal debt deflated by CPIF, $d_{t}=D_{t} / P_{t}^{C P I F}$ ), the log of real house prices (house prices deflated by CPIF, $p_{t}=$ $\left.P_{t} / P_{t}^{C P I F}\right)$. The baseline BVAR is estimated with 4 lags on data for the period $1995 Q 1-2013 Q 1$. Recursive (Cholesky) contemporaneous restrictions are used to identify the effects of a monetary policy shock. Our assumptions imply that house prices and debt are restricted from responding immediately to a monetary policy shock, whereas monetary policy can react immediately to all the variables. ${ }^{7}$ An alternative identification scheme, which allows for contemporaneous two-way interaction between the repo rate and house prices, is provided by Björnland and Jacobsen $[2]^{8}$. Note that foreign and Swedish GDP, and real house prices and debt, enter the model in levels. This

\footnotetext{
${ }^{7}$ Lantmäteriet is responsible for maintaining a register containing information about real property, such as ownership and mortgages. When a house change owners, the change in ownership and the purchase price is registered at Lantmäteriet who in turn reports this information to Statistics Sweden. The registration is done when a new deed is prepared, which normally takes place about two to three months after the time when the purchase contract was written. The deed shows the purchase price and the date the deed was constructed, not the date the purchase was made and the purchase contract was written. The result of this is that statistics based on title deeds, which is what we use in this paper, is lagging statistics based on the date of the purchase contract. Hence, house prices are predetermined one quarter and cannot, by construction, react to unanticipated monetary policy shocks in the same quarter.

${ }^{8}$ Björnland and Jacobsen [2] do not include a measure of debt in their model. They allow for contemporaneous two-way interaction between the interest rate, and the exchange rate and house prices, respectively. In order to identify their model they therefore need to apply so called long-run restrictions. In particular, they assume that monetary policy cannot affect either the real exchange rate or the level of real GDP in the long run.
} 
implies that a monetary policy shock cannot affect the levels of these variables in the long-run. See the appendix for a more formal description of the model.

In Figure 6 and 7 the estimated effects of a monetary policy shock on the variables in the model are displayed (black, solid, lines). In Figure 6 the effects of a one standard deviation monetary policy shock are provided, while in Figure 7 we attempt to simplify a comparison with Svensson by displaying the effects of increasing the interest rate by one percentage point during year 1 (i.e. quarter 1 to 4), and then return back to the baseline in year 2. A positive monetary policy shock leads to a (temporary) decrease in GDP, and a decrease in inflation. These responses have the expected sign. Further, both real house prices and real household debt fall in response to the positive policy shock, and the magnitude of the responses for these two variables are quite similar. ${ }^{9}$ Hence, the BVAR model roughly supports conventional wisdom, although the GDP and CPIF inflation responses are somewhat smaller than the responses which Svensson use. ${ }^{10}$

In order to understand the implications of the assumptions underlying the debt deflation effect of monetary policy we proceed by replacing the actual debt time series in the BVAR with two counterfactual debt series, namely the series generated previously using the debt model presented above. In particular, we use the two model-implied debt series displayed in Figure 2 (where the mortgage holding period equals $T=28)$ and Figure $3(T=15)$, respectively. All other aspects of the model and the data are kept as above. The effects of a monetary policy shock are presented in Figure 6 and 7. The responses for GDP, inflation and real house prices are very similar to those above. However, in the case of the very persistent debt series generated with Svensson's calibration $(T=28)$, the effect of a monetary policy shock on real debt is now reversed. A positive monetary policy shock, which increases the repo rate, now increases real debt (temporarily). The reason is that a tighter policy induces a very slow fall of total nominal (mortgage) debt, but a faster fall in the nominal price level and nominal GDP. However, using a debt series which fits the dynamics in the data better, i.e. the series based on the 'optimal' calibration of the model $(T=15)$, the results are less clear cut. In this case real debt falls following a positive monetary policy shock, while the effects are smaller than in the case with actual data on debt.

The counterfactual debt series are generated using the debt model, where the conditional independence assumption in (4.2) is implicitly embedded, as discussed above. One interpretation of

\footnotetext{
${ }^{9}$ In the BVAR model the debt measure used is total household financial debt. As a sensitivity check we have also used a measure of mortgage debt in the BVAR model. The results concerning the effects of monetary policy on debt are found to be largely the same in these two cases.

${ }^{10}$ Svensson use the responses from the Riksbank's macroeconomic model, Ramses, for CPIF inflation and GDP. House prices and debt are not modelled in Ramses. Instead of mixing responses for different variables from different sources, here we estimate the effects for all the relevant variables within a single model.
} 
the counterfactual debt series is that this series captures the component of debt which is attributed to movements in housing prices. Instead of making inference in the BVAR model based on the counterfactual series, an alternative is to impose the conditional independence assumption, (4.2), through restrictions on the parameters of the BVAR model, and estimate it using actual data. ${ }^{11}$ In both cases the effect of changes in the repo rate on debt, which do not feed through via their effects on housing prices, are assumed away. In Figure 8 the estimated responses for the restricted BVAR model are presented, and the responses for the BVAR with counterfactual debt $(T=15)$ are included for comparison. Interestingly, the responses are strikingly similar in these two cases: real debt and the debt-to-GDP ratio remain unaffected by the higher policy rate for roughly $1-2$ years, before they start to fall.

In summary, if the true data-generating process for debt had been the one envisaged by Svensson, it appears that the BVAR model would have correctly identified the effects of monetary policy, at least in the sense that the qualitative effects estimated with the BVAR model are similar to the ones computed by Svensson. However, the BVAR model estimated on actual data produce responses of real debt and the debt-to-GDP ratio which run counter to the responses suggested by Svensson. This, again, signals that the debt model fails to capture all aspects of debt fluctuations which monetary policy may affect.

\section{Conclusions}

In this note we have offered some comments and extensions to Lars Svenssons's analysis, where he argues that "Leaning against the wind" leads to higher real household debt and a higher household debt-to-GDP ratio. Svensson's analysis rests on two key assumptions. First, the effects of monetary policy on mortgage debt works only through its effects on housing prices. Second, a relatively small fraction of the debt stock is turned over each year. These assumptions imply that nominal debt is a sticky variable which falls slowly in response to a monetary policy shock which increases the repo rate. The price level and, in particular, nominal GDP fall faster and, hence, real debt and the debt-to-GDP ratio increase (rather than decrease).

The experiments in this paper illustrate the importance of the dynamic properties of debt for the results in Svensson [9]. We take Svensson's debt model to the data and show that the model provides an incomplete account of short term debt dynamics. In particular, we apply Svensson's

\footnotetext{
${ }^{11}$ A caveat here is that Svensson's conditional independence assumption concerns nominal debt, and not real debt. In order to impose long run restrictions on real debt in the BVAR model it is necessary here to impose the restrictions on the parameters in the equation for real debt.
} 
calculation of the effect of changes in housing prices on debt in order to obtain a debt growth series. The resulting series is too persistent when compared to actual debt data. It is therefore questionable to use the debt model for the purpose of computing responses of debt to a temporary policy rate shock. The exact responses of real debt and the debt-to-GDP ratio further depend crucially on the responses of prices and GDP. Here we have chosen to use a BVAR model in order to compute the effects for all the relevant variables within a coherent framework. Whether our results justify a "Leaning against the wind" policy or not remains an open question. Our point here is simply that it is important to to understand the short term dynamics of debt, in order to obtain responses of debt which are consistent with the debt data.

Several interesting topics for future research emerge. First, a serious quantification of the effect of 'structural' factors (e.g. the transformation of rental into tentant-owned apartments) for the increase in debt levels seen in the past $15-20$ years appears to be needed. Interestingly, in the debt model a single variable, housing prices, can account for the overall trend increase in debt in the past $15-20$ years, while other studies attribute a substantial share of the increase to 'structural' factors, see e.g. [6]. Second, it appears necessary to better understand the impact of interest rate changes on equity withdrawals and leverage, i.e. the choice of LTV-ratio, of households. Third, the analysis of the effects of monetary policy on debt within the VAR framework could be extended and alternative hypotheses about the interaction between monetary policy and debt could be tested in a more formal way. For example, novel Bayesian variable selection and/or model averaging techniques could be applied to study these issues in more depth, see e.g. the methods of Korobilis [7]. 


\section{Appendix}

\section{A. Data}

In order to simplify identification of the data series used, or referred to, in the paper we provide the SDMX (Statistical Data and Metadata Exchange) code which exactly identifies the data series. SDMX is a standard for the representation of statistical data and metadata, adopted by seven major institutions (including ECB, BIS, IMF) as well as Sveriges Riksbank.

\section{A.1. House prices and debt}

The data series for housing prices is the price of owner-occupied one- and two-dwelling buildings in Sweden (SDMX code: RPP1.Q.SE.N.RB_OO_OTD.00.1.RB_INX.OUTC.NA, 'fastighetsprisindex'). Concerning (nominal) debt we have considered the following series:

- Total household financial debt $(F)$. SDMX code: ESA1.Q.SE.N.1400.RB_FT0001R1.0000.TTTT.V.N.A.OUTC.NA.

- Loans to Swedish households $(L)$.

- Mortgage debt: housing loans to Swedish households $(M)$.

Loans to Swedish households consists of consumer credit $(C)$, mortgage loans $(M)$ and 'other' loans $(O)$, i.e.

$$
L=C+M+O
$$

The source of these data series is the SCB Financial Market Statistics (September 2013), [13].

- L: SCB Financial Market Statistics (FMS), Section 4.3 Lending to Swedish households and public sector broken down by sub sectors.

- $M$ : SCB FMS, Section 4.7 Lending to households incl. NPISH broken down by the sector of the lender and purpose, SEK millions, column 'housing'.

- $C$ : SCB FMS, Section 4.7 Lending to households incl. NPISH broken down by the sector of the lender and purpose, SEK millions, column 'consumption'. 
In June 2013 the stocks, in millions of SEK, were (with percentage of total in parenthesis):

$$
2,831,289=171,634(6,1)+2,278,429(80.5)+381,225(13.5)
$$

The relationship between total household financial debt $(F)$ and loans to Swedish households $(L)$ is

$$
F=L+R
$$

where $R$ is a 'residual'. Total household financial debt $(F)$ was 3, 131, 201 MSEK in June 2013, i.e. loans to Swedish households $(L)$ constitutes roughly $90 \%$ of $F$. The remainder, $R$, consists mainly of student loans (CSN loans).

Total household financial debt, $F$, is available on a quarterly basis from 1980Q1. There is an obvious break in the series in $2001 Q 1$ due to changes in the accounting of taxes. Loans to Swedish households, $L$, is available on a yearly basis from 1975 to 1991, on a quarterly basis from 1992 to 2001, and on a monthly basis from 2001M12. It consists of lending from banks, housing credit institutions and finance companies (monetary and financial institutions, MFI).

Mortgage debt, $M$, is available on a monthly basis from $2001 M 12$ (FMS, Section 4.7). In order to construct a longer time series of mortgage debt, for the period 1998M1 to $2001 M 12$ one may use monthly data on housing credit institutions' lending to households as a proxy for total mortgage debt (FMS, Section 4.3.1). In 2001M12 housing credit institutions' lending to households amounted to 670,956 MSEK, while MFIs housing-related lending amounted to 712,770 MSEK, which means that there would be a break in a series constructed by combining the two series. For 1996 and 1997 one may use monthly data on housing credit institutions' lending to households, including NPISH. For 1975 to 1991 this data series is available at a yearly frequency and between 1992 and 1995 the data is available at a quarterly frequency.

The mortgage debt series is quite erratic for the period $2001 M 12$ and onwards. Some of the major 'outliers' (on a quarterly frequency) are 2001Q4 (when the series begins), 2004Q4 (improvement in Banks' reporting of lending broken down by collateral occurred) and 2005Q4. These are explained in more detail in the SCB Financial Market Statistics, [13], p. 112.

In Figure $\mathrm{A} 1$ the debt measures $F, L$ and $M$, expressed in million SEK, are plotted. In Figure A2 the series are displayed in quarterly growth rates. In the latter figure the 'outliers' discussed above are immediately visisble.

In the paper we choose to focus on the measure $F$, and the outlier in $2001 Q 1$ is handled when constructing the debt growth series used for the analysis. Judging from Figure A2 the time series 
properties of the three series are not radically different, e.g. mortgage debt growth is not smoother than the other two measures.

\section{A.2. LTV-ratios on new loans, average LTV-ratios and a measure of the turnover rate of debt}

The data series on the loan-to-value ratio for new loans, $\gamma_{\text {data }}$, is obtained from the data appendices accompanying 'The Swedish Mortgage Market', Finansinspektionen [4] and [5]. It is the volumeweighted loan-to-value ratio. Data on new mortgage loans, $m_{\text {data }}$, is obtained from the same sources. It is the volume of 'strict new loans'. The definition of new loans is that these 'are loans taken by strict new borrowers and existing borrowers that have increased the loan-to-value ratio on the existing collateral by more than 50 percent', see Finansinspektionen, [5]. To compute our measure of the turnover rate of debt, $\gamma_{\text {data }}$, we use the stock of mortgage debt, which is obtained from the SCB Financial Market Statistics (Section 4.8. MFIs' lending for housing loans to Swedish households broken down by maturity, SEK millions.). The data series are provided in Table 3.

Table 3 LTV-ratio on new loans, strict new loans, mortgage debt and the debt turnover rate

\begin{tabular}{llllll}
\hline \hline \multicolumn{2}{l}{ LTV-ratio new loans, $\gamma_{\text {data }}$} & \multicolumn{2}{l}{ Strict new loans, $m_{\text {data }}$} & Mortgage debt, $M$ & Debt turnover rate, $\%, \gamma_{\text {data }}$ \\
$2002-12-31$ & 59.2 & $2009 Q 1$ & $89347($ MSEK) & 1718124 (MSEK) & 20.8 \\
$2003-12-31$ & 60.7 & $2009 Q 2$ & 118768 & 1768512 & 26.9 \\
$2004-12-31$ & 62.4 & $2009 Q 3$ & 102798 & 1807126 & 22.8 \\
$2005-12-31$ & 65.5 & $2009 Q 4$ & 118304 & 1856770 & 25.5 \\
$2006-12-31$ & 67.2 & $2010 Q 1$ & 93713 & 1894693 & 19.8 \\
$2007-12-31$ & 68.6 & $2010 Q 2$ & 114870 & 1941867 & 23.7 \\
$2008-12-31$ & 70.2 & $2010 Q 3$ & 109907 & 1977297 & 22.2 \\
$2009-12-31$ & 70.8 & $2010 Q 4$ & 113035 & 2016525 & 22.4 \\
$2010-12-31$ & 71.0 & $2011 Q 1$ & 85327 & 2038918 & 16.7 \\
$2011-12-31$ & 68.9 & $2011 \mathrm{Q} 2$ & 100375 & 2071262 & 19.4 \\
$2012-09-30$ & 68.8 & $2011 \mathrm{Q} 3$ & 93918 & 2098198 & 17.9 \\
& & $2011 \mathrm{Q} 4$ & 93565 & 2125706 & 17.6 \\
& $2012 \mathrm{Q} 1$ & 81321 & 2143857 & 15.2 \\
& $2012 \mathrm{Q} 2$ & 94797 & 2171137 & 17.5 \\
\hline \hline
\end{tabular}

\section{A.3. Other data series}

The following variables, and corresponding data series, are used in the BVAR model: 
- The log of foreign GDP. Foreign GDP is a trade-weighted average of GDP, where KIX-weights are used.

SDMX code: ESA1.Q.RB_KIX.Y.0000.B1QG00.1000.TTTT.Q.N.A.OUTC.NA.

- KIX-weighted quarterly CPI inflation.

SDMX code: ICP1.Q.RB_KIX.Y.RB_S000000.2.INX.OUTC.NA.

- KIX-weighted short-term interest rate.

SDMX code: FMD2.Q.RB_KIX.SEK.RB_TR.RB_KR.RB_ED.HSTA.OUTC.NA.

- The log of GDP.

SDMX code: ESA1.Q.SE.Y.0000.B1QG00.1000.TTTT.Y.N.A.OUTC.LS.

- Quarterly CPIF inflation.

SDMX code: ICP1.Q.SE.Y.RB_FS000000.1.INX.OUTC.NA.

- Debt and house prices. See previous subsection.

- The repo rate.

SDMX code: FMD2.Q.SE.SEK.RB_TR.RB_KR.RB_ED.HSTA.OUTC.NA.

\section{B. The turnover rate of nominal debt}

The turnover rate of debt is defined as

$$
\gamma_{t}^{d}=\frac{m_{t}}{D_{t}}=\frac{\alpha_{t} \frac{V_{t}}{T}}{\sum_{s=0}^{T-1} \alpha_{t-s} \frac{V_{t-s}}{T}(1-\beta)^{s}},
$$

see equation 2.10 in the main text.

Assuming constant house price growth, $g>0,{ }^{12}$ along with a constant housing stock normalised to unity, $H_{t}=1$, a constant LTV ratio for new mortgage loans, $\alpha_{t}=\alpha$ and no amortisations, $\beta=0$, this simplifies to

$$
\gamma_{t}^{d}=\frac{\alpha \frac{P_{t}}{T}}{\frac{\alpha}{T} \sum_{s=0}^{T-1} P_{t-s}}=\frac{P_{t}}{\sum_{s=0}^{T-1} P_{t-s}}=\frac{P_{t}}{P_{t} \frac{1+g-(1+g)^{-T+1}}{g}}=\frac{g}{1+g-(1+g)^{-T+1}},
$$

\footnotetext{
${ }^{12}$ In the case where nominal house prices $P_{t}$ grow with a constant nominal growth rate, $g$, they satisfy $P_{t}=$ $P_{0}(1+g)^{t}$.
} 
where the expression for the sum of a geometric series is used. From Svensson we have

$$
A_{t}=A=\frac{\alpha}{T} \frac{1+g-(1+g)^{-T+1}}{g},
$$

and hence the average LTV ratio, $A$, the LTV ratio on new loans, $\alpha$, the turnover rate of the housing stock, $1 / T$, and the turnover rate of nominal debt, $\gamma^{d}$, are related through

$$
A=\frac{\alpha}{T \gamma^{d}}
$$

or

$$
\gamma^{d}=\frac{\alpha}{A} \frac{1}{T}
$$

\section{The BVAR model}

The BVAR model used in this paper is of the form

$$
\Pi(L) x_{t}=A \varepsilon_{t},
$$

where $x_{t}=\left(y_{t}^{f}, \pi_{t}^{f}, i_{t}^{f}, y_{t}, \pi_{t}, d_{t}, p_{t}, i_{t}\right)^{\prime}$ is an $n$-dimensional vector $(n=8)$ of time series, $\Pi(L)=$ $I_{n}-\Pi_{1} L-\ldots-\Pi_{k} L^{k}$, and $L$ is the back-shift operator $(k=4)$. The structural disturbances $\varepsilon_{t} \sim$ $N_{n}\left(0, I_{n}\right), t=1, \ldots, T$, are assumed to be independent across time. We impose restrictions on $\Pi(L)$ such that the foreign economy is exogenous. $A$ is the lower-triangular (Cholesky) contemporaneousimpact matrix, such that the covariance matrix $\Sigma$ of the reduced-form disturbances decomposes as $\Sigma=A A$. The prior proposed by Litterman [8] will be used on the dynamic coefficients in $\Pi$, with the default values on the hyperparameters in the priors suggested by Doan [3]: overall tightness is set to 0.2 , cross-equation tightness to 0.5 , and a harmonic lag decay with a hyperparameter equal to 1 . 


\section{References}

[1] Adolfson, Malin, Laséen, Stefan, Christiano, Lawrence, Trabandt Mattias, and Walentin, Karl, (2013), "Ramses II: Model description", Occasional Paper nr 12, Sveriges riksbank.

[2] Bjørnland, Hilde C. \& Jacobsen, Dag Henning, (2010). "The role of house prices in the monetary policy transmission mechanism in small open economies," Journal of Financial Stability, Elsevier, vol. 6(4), pages 218-229, December.

[3] Doan, Thomas A. (1992). RATS User's Manual. Version 4. Evanston, IL: Estima.

[4] Finansinspektionen, The Swedish Mortgage Market 2012, March 132012 (http://www.fi.se).

[5] Finansinspektionen, The Swedish Mortgage Market 2013, March 72013 (http://www.fi.se).

[6] Finansinspektionen, PM 1 - Förklaringar till utvecklingen av hushållens skuldsättning sedan mitten av 1990-talet.

[7] Korobilis, Dimitris (2013). "VAR forecasting using Bayesian variable selection," Journal of Applied Econometrics, volume 28, pages 204-230, March.

[8] Litterman, Robert B. (1986). "Forecasting with Bayesian Vector Autoregressions-Five Years of Experience." Journal of Business and Economic Statistics 4 (1): 25-38.

[9] Svensson, Lars E.O. (2013a), "'Leaning against the wind' increases (not reduces) the household debt-to-GDP ratio," working paper, www.larseosvensson.net.

[10] Svensson, Lars E.O. (2013b), "The Effect on Housing Prices of Changes in Mortgage Rates and Taxes," working paper, www.larseosvensson.net.

[11] Sørensen, Peter Birch (2013), "The Swedish Housing Market: Trends and Risks," Report to Finanspolitiska rådet 2013/5, Finanspolitiska rådet, www.finanspolitiskaradet.se.

[12] Walentin, Karl (2013), "Housing Collateral and the Monetary Transmission Mechanism", Scandinavian Journal of Economics, forthcoming.

[13] SCB, Financial Market Statistics September 2013, October 252013 (http://www.scb.se) 
D. Figures 
Figure 1. Housing prices, total debt and the average LTV ratio. Calibration as in Svensson (2013a).
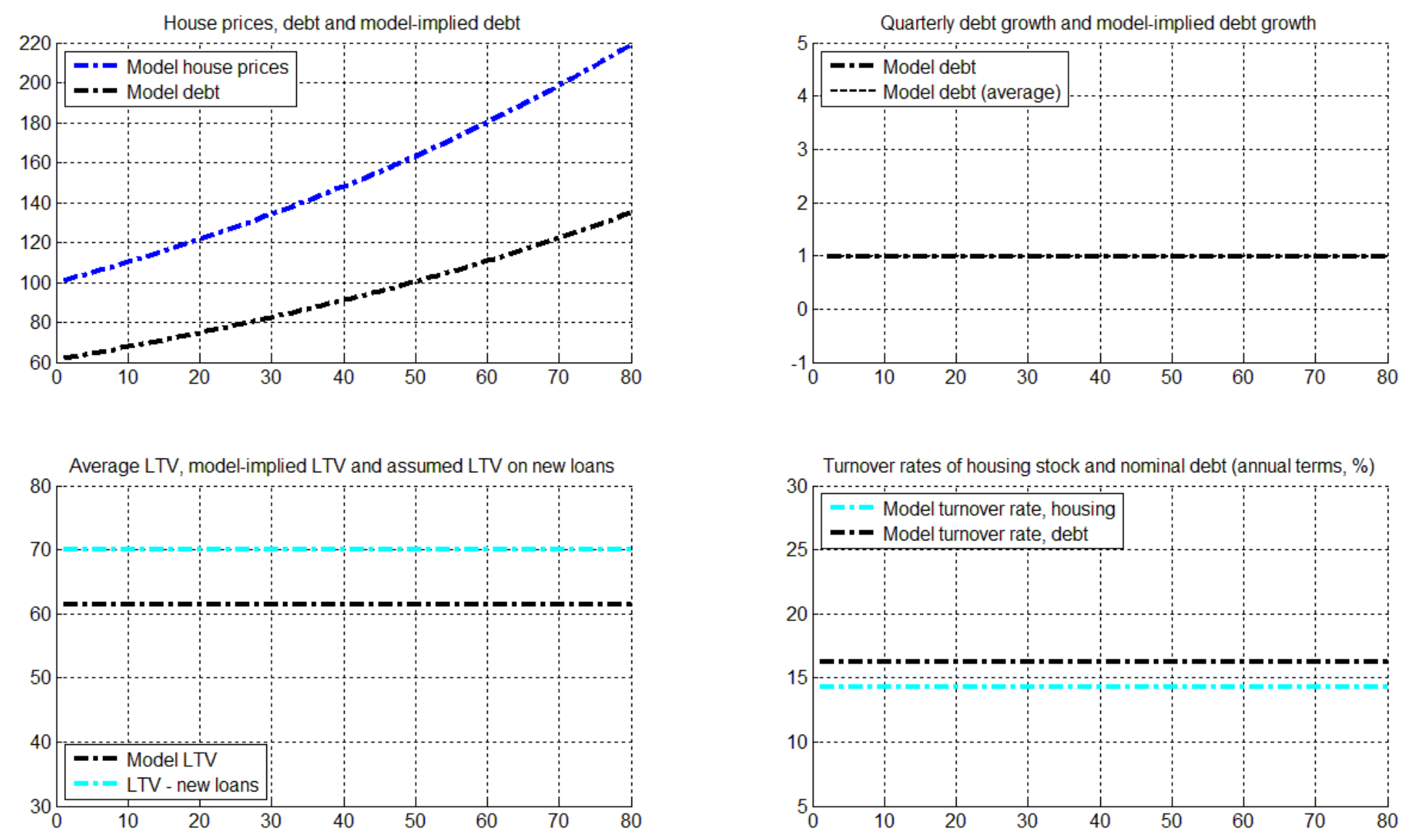

Note: The following assumptions are made: a constant LTV-ratio on new mortgages, $\alpha=70 \%$, and a housing holding period of 7 years, which corresponds to $T=4 \times 7=28$ quarters, housing prices grow by $4 \%$, which corresponds to a quarterly growth rate of $0.985 \%$. 
Figure 2. Actual house price data and implied total debt, average LTV ratio and turnover rates of housing and nominal debt. Svensson's calibration.
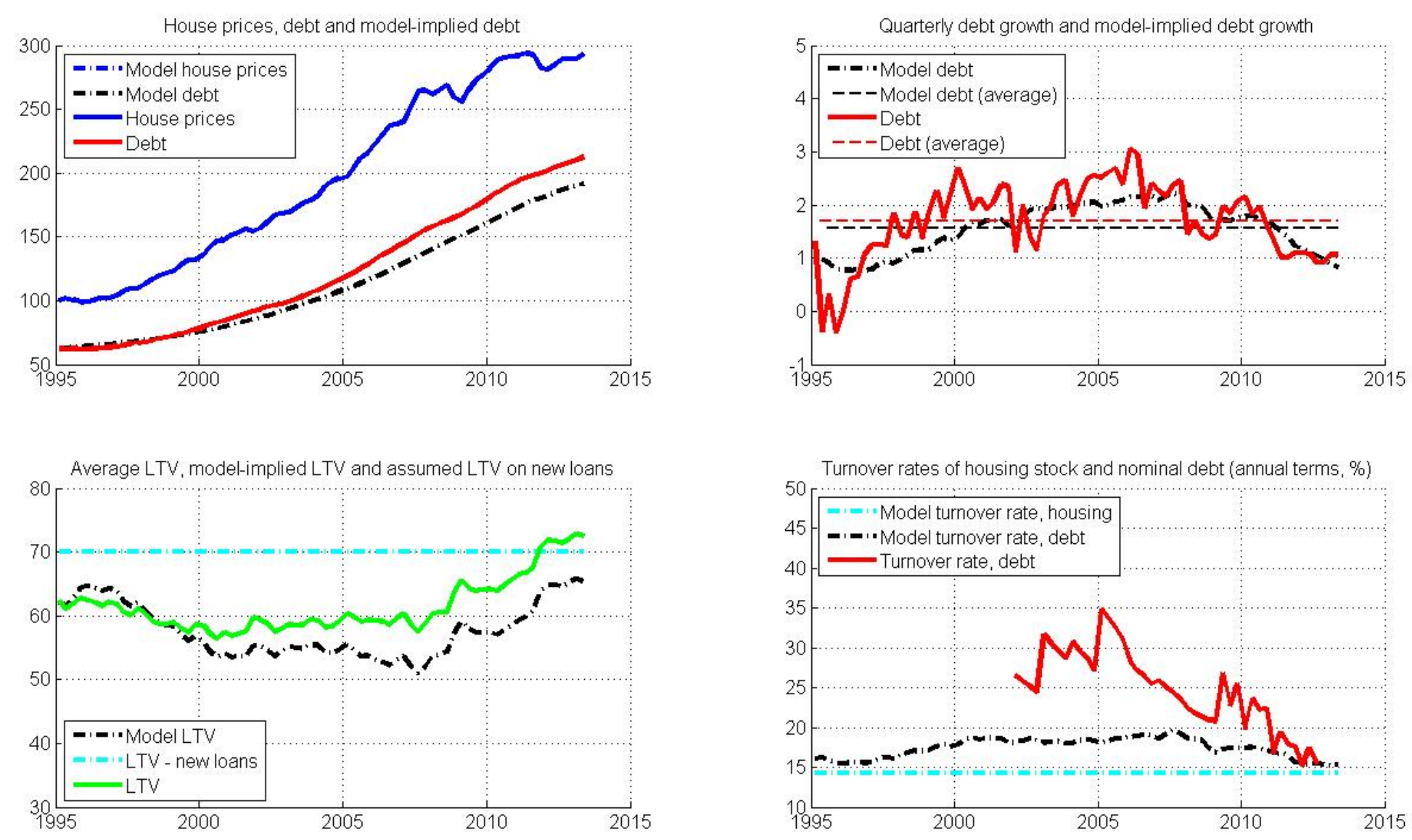

Note: The following assumptions are made: a constant LTV-ratio on new mortgages, $\alpha=70 \%$, and a housing holding period of 7 years, which corresponds to $T=4 \times 7=28$ quarters, housing prices are actual housing prices (fastighetsprisindex). The turnover rate of debt series is calculated as new mortgages (data from Finansinspektionen) over total housing loans to Swedish households (data from Statistics Sweden).

Source: Statistics Sweden and Finansinspektionen. 
Figure 3. Actual house price data and implied debt, average LTV ratio and turnover rates of housing and nominal debt. Calibration selected to obtain the best correspondence between model-implied debt and the actual debt series.
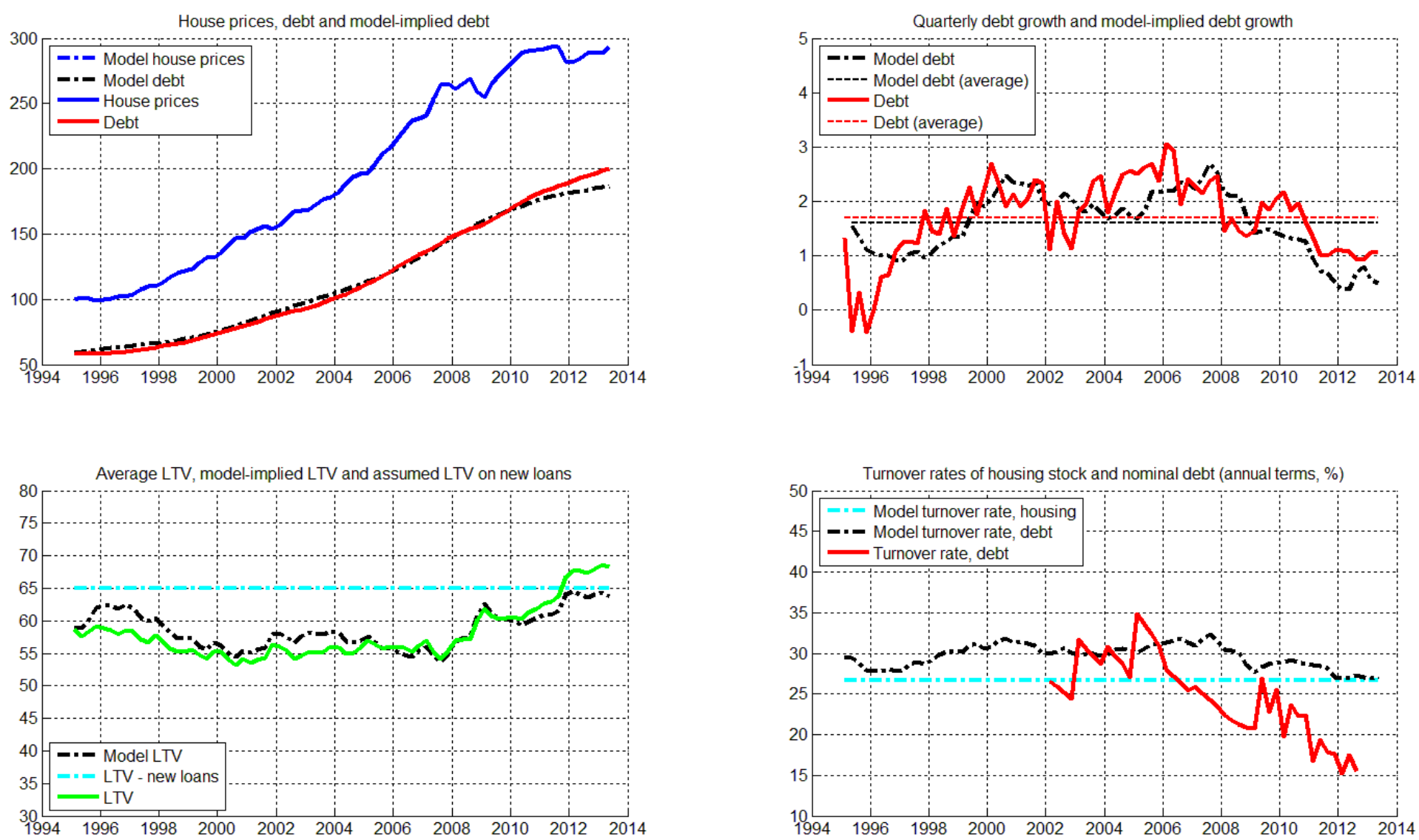

Note: The following assumptions are made: a constant LTV-ratio on new mortgages, $\alpha=65 \%$, the housing holding period $(T=15)$ is chosen to fit the level of actual debt by minimizing eq. (3.1), housing prices are actual housing prices (fastighetsprisindex). The turnover rate of debt series is calculated as new mortgages (data from Finansinspektionen) over total housing loans to Swedish households (data from Statistics Sweden).

Source: Statistics Sweden and Finansinspektionen. 
Figure 4. LTV for new mortgage loans in the data and LTV implied by the model given house price and debt data. Svensson's calibration.

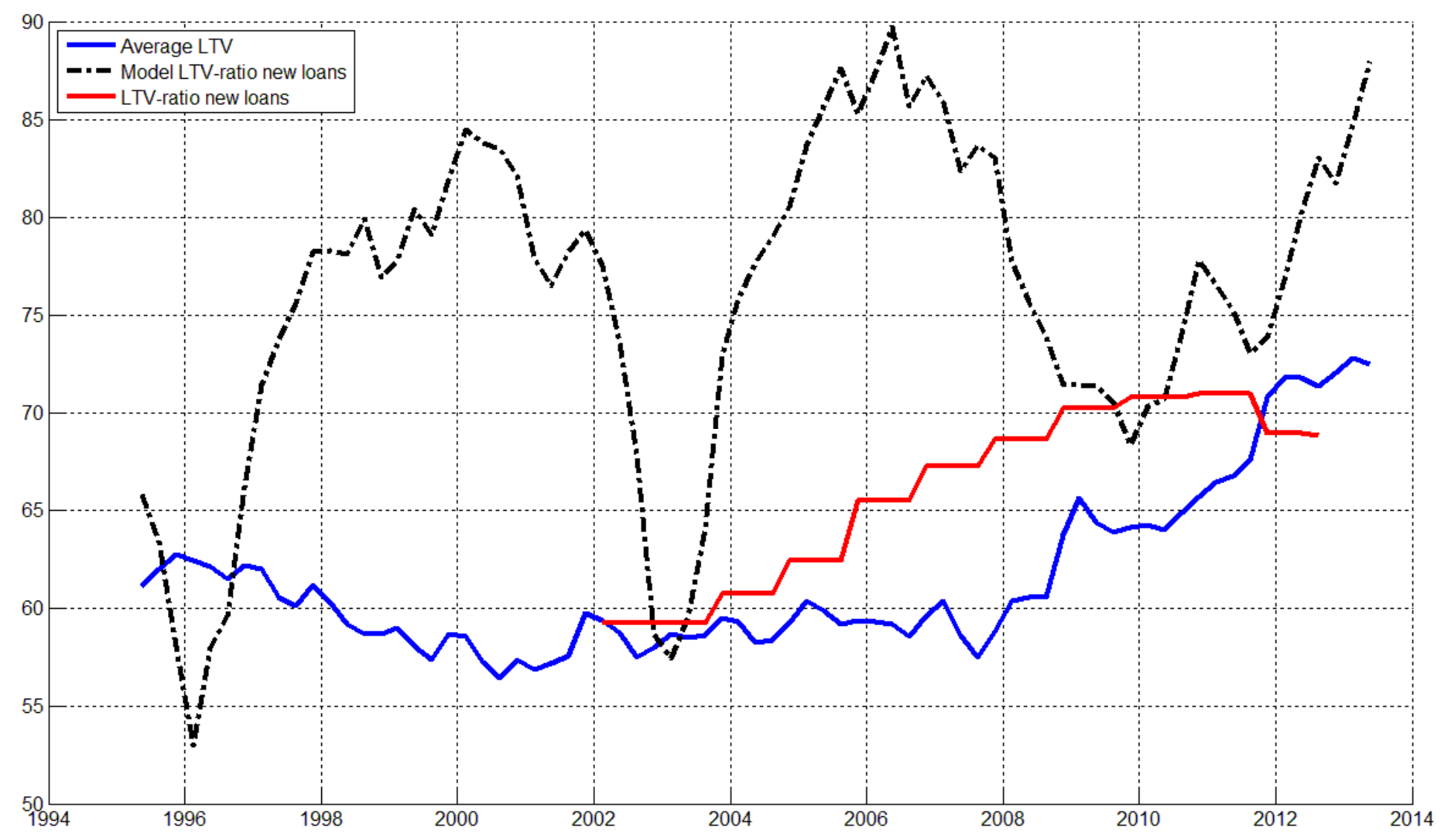

Note: The model implied debts series is calculated using Svensson's baseline assumptions: a constant LTV-ratio on new mortgages, $\alpha=70 \%$, the housing holding period equals 7 years, which corresponds to $T=4 \times 7=28$ quarters. Housing prices are actual housing prices (fastighetsprisindex). Model LTV-ratio of new loans is 4-quarter average. LTV on new loans, yearly data (from Finansinspektionen).

Source: Finansinspektionen 
Figure 5. LTV for new mortgage loans in the data and LTV implied by the model given house price and debt data. Calibration selected to obtain the best correspondence between model-implied debt and the actual debt series.

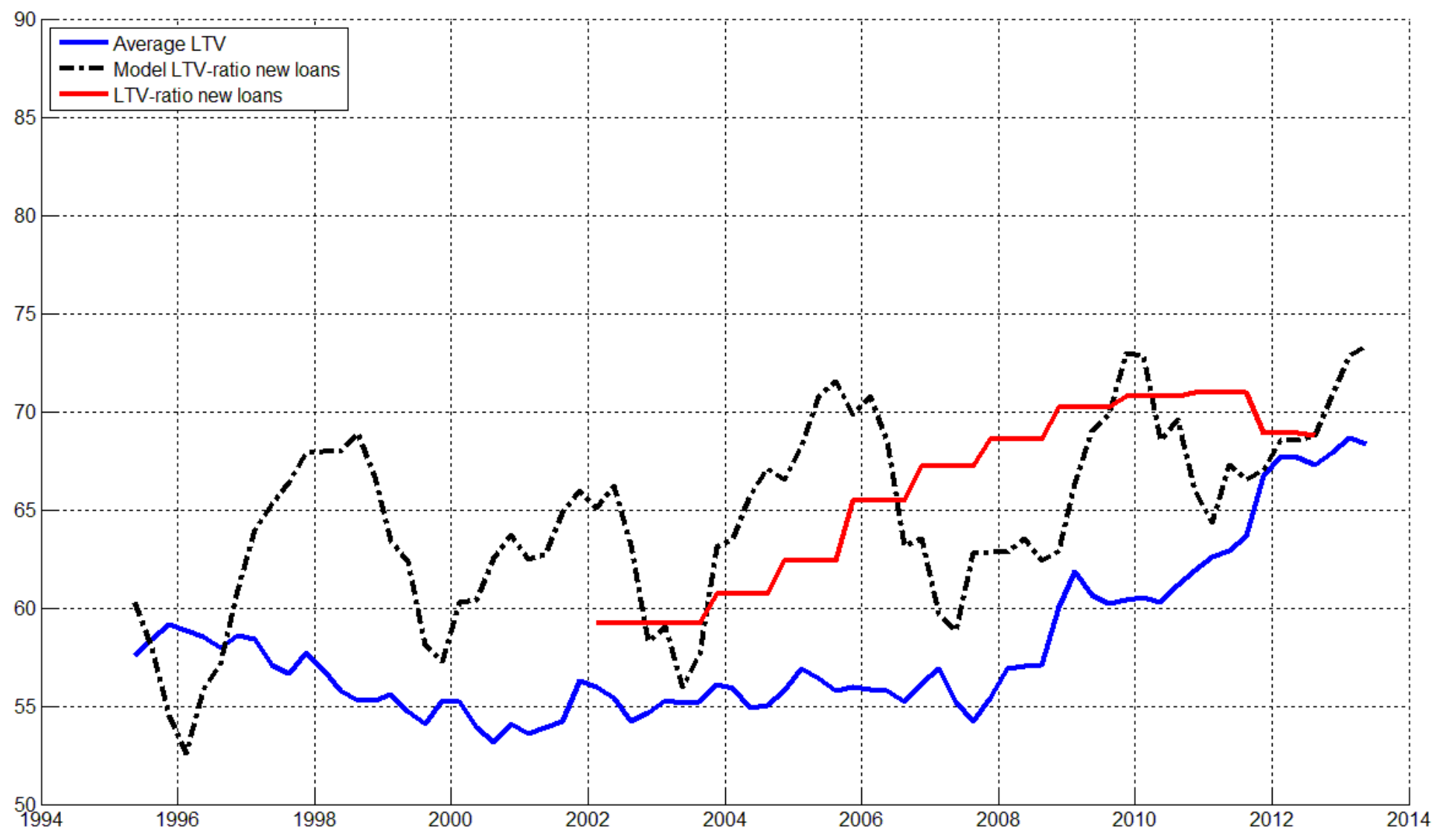

Note: The model implied debts series is calculated using the best fit calibration: a constant LTV-ratio on new mortgages, $\alpha=65 \%$, the housing holding period $(\mathrm{T}=15)$ is chosen to fit the level of actual debt by minimizing eq. (3.1). Housing prices are actual housing prices (fastighetsprisindex). Model LTV-ratio of new loans is 4-quarter average. LTV on new loans, yearly data (from Finansinspektionen). 
Figure 6. Posterior mean impulse-response functions to a one-standard-deviation interest rate shock for the domestic variables in the BVAR and implied ratios such as Debt/GDP and LTV ratios.
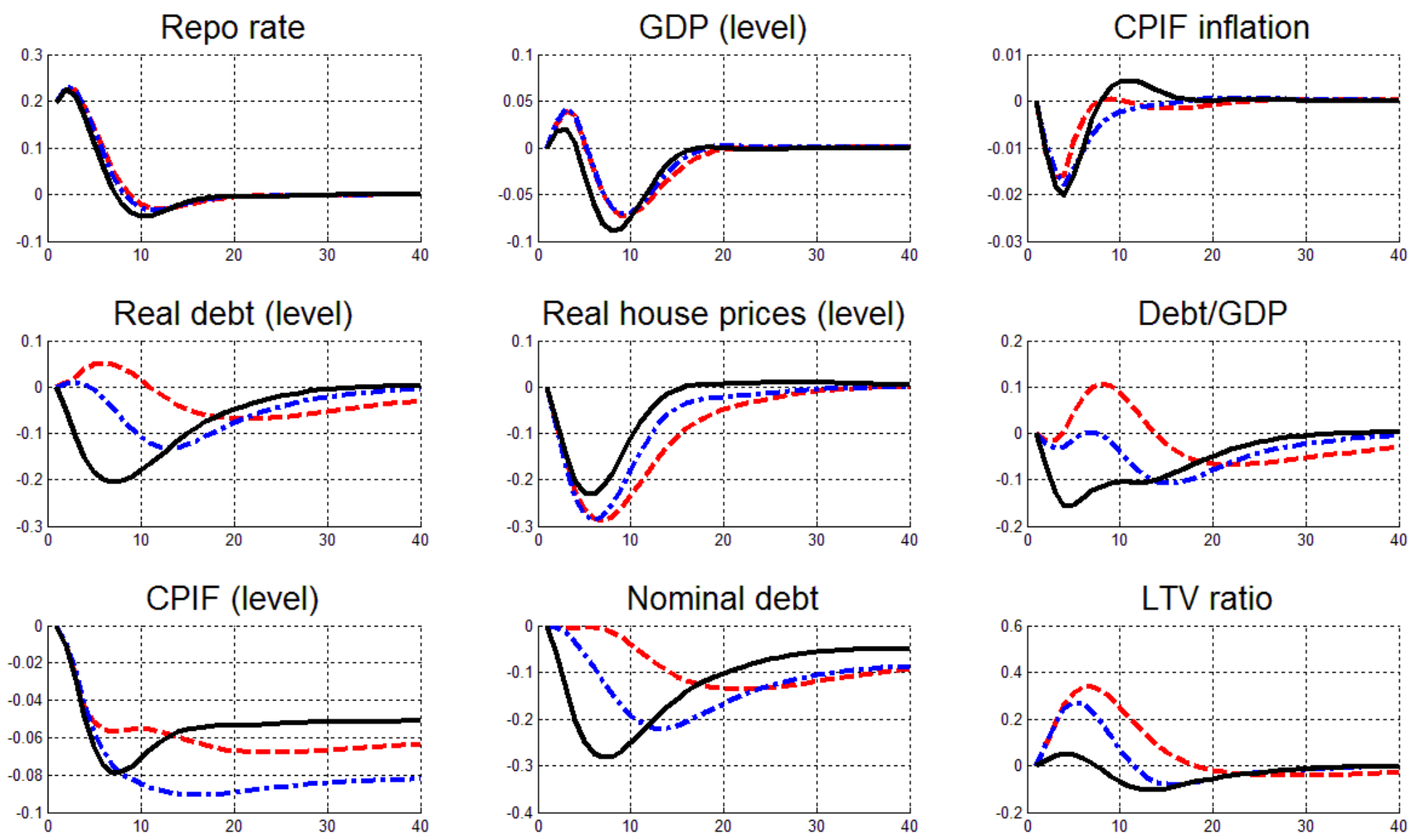

Note: The monetary policy responses are for the BVAR model with debt data (black), with simulated debt data $(\mathrm{T}=28, \alpha=70 \%$, red) and with simulated debt data $(\mathrm{T}=15, \alpha=65 \%$, blue $)$. 
Figure 7. Posterior mean impulse-response functions to a one-percentage point higher interest rate during four quarters for the domestic variables in the BVAR and implied ratios such as Debt/GDP and LTV ratios.
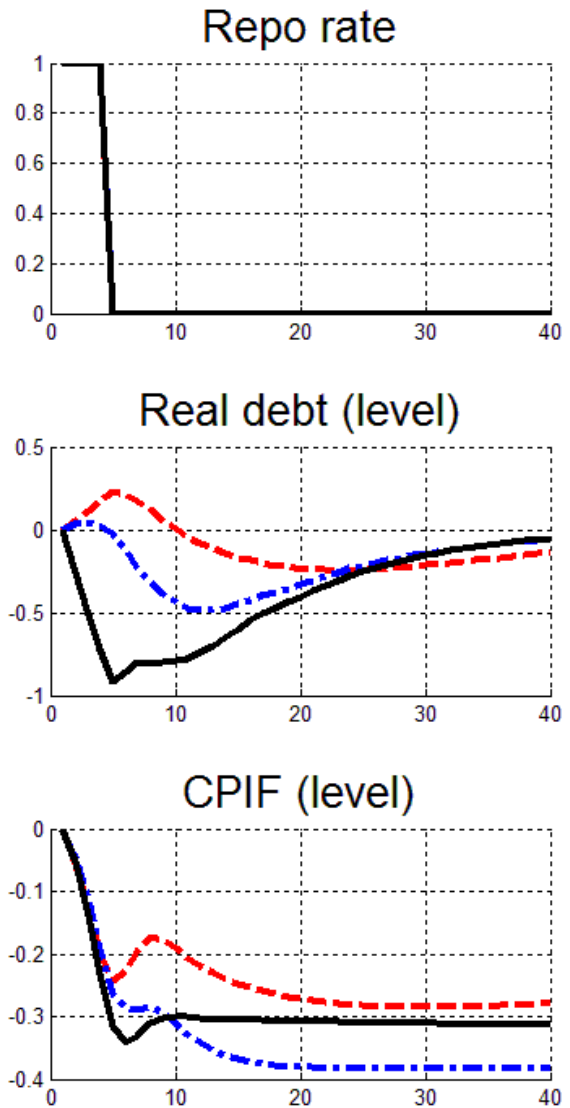

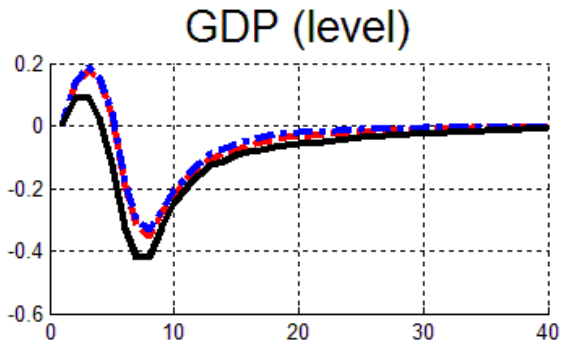

Real house prices (level)

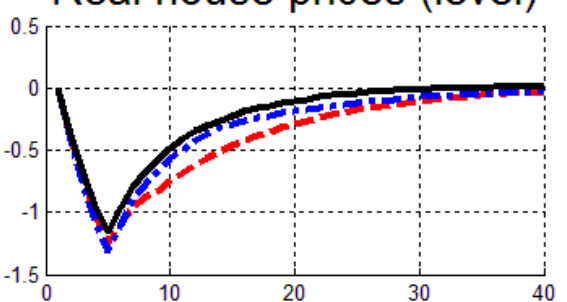

Nominal debt

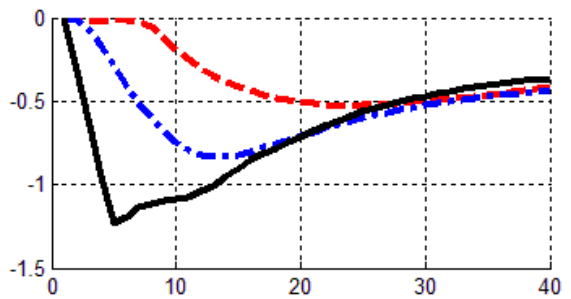

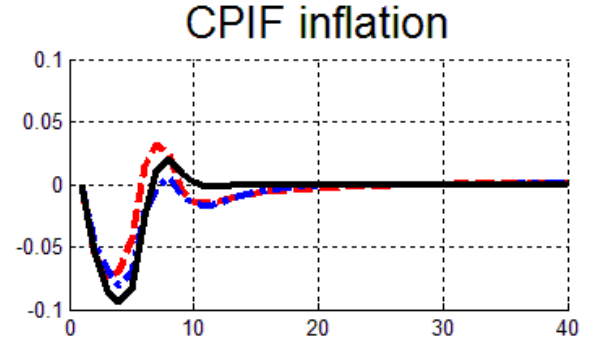

Debt/GDP

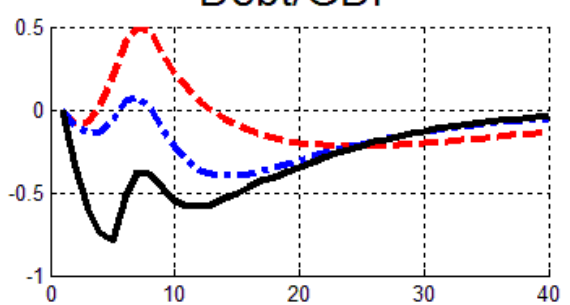

LTV ratio

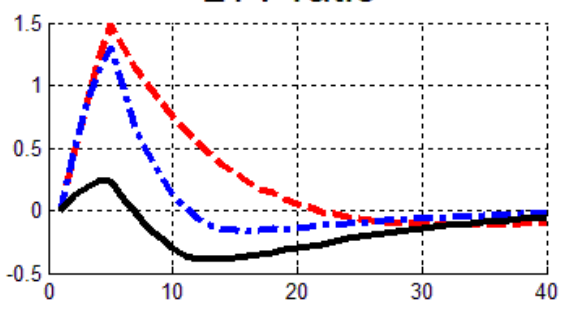

Note: The monetary policy responses are for the BVAR model with debt data (black), with simulated debt data $(\mathrm{T}=28, \alpha=70 \%$, red) and with simulated debt data $(T=15, \alpha=65 \%$, blue). The responses are standardized such that the repo rate is one percentage point above baseline for a year. 
Figure 8. Posterior mean impulse-response functions to a one-percentage point higher interest rate during four quarters in the BVAR and in a restricted BVAR.
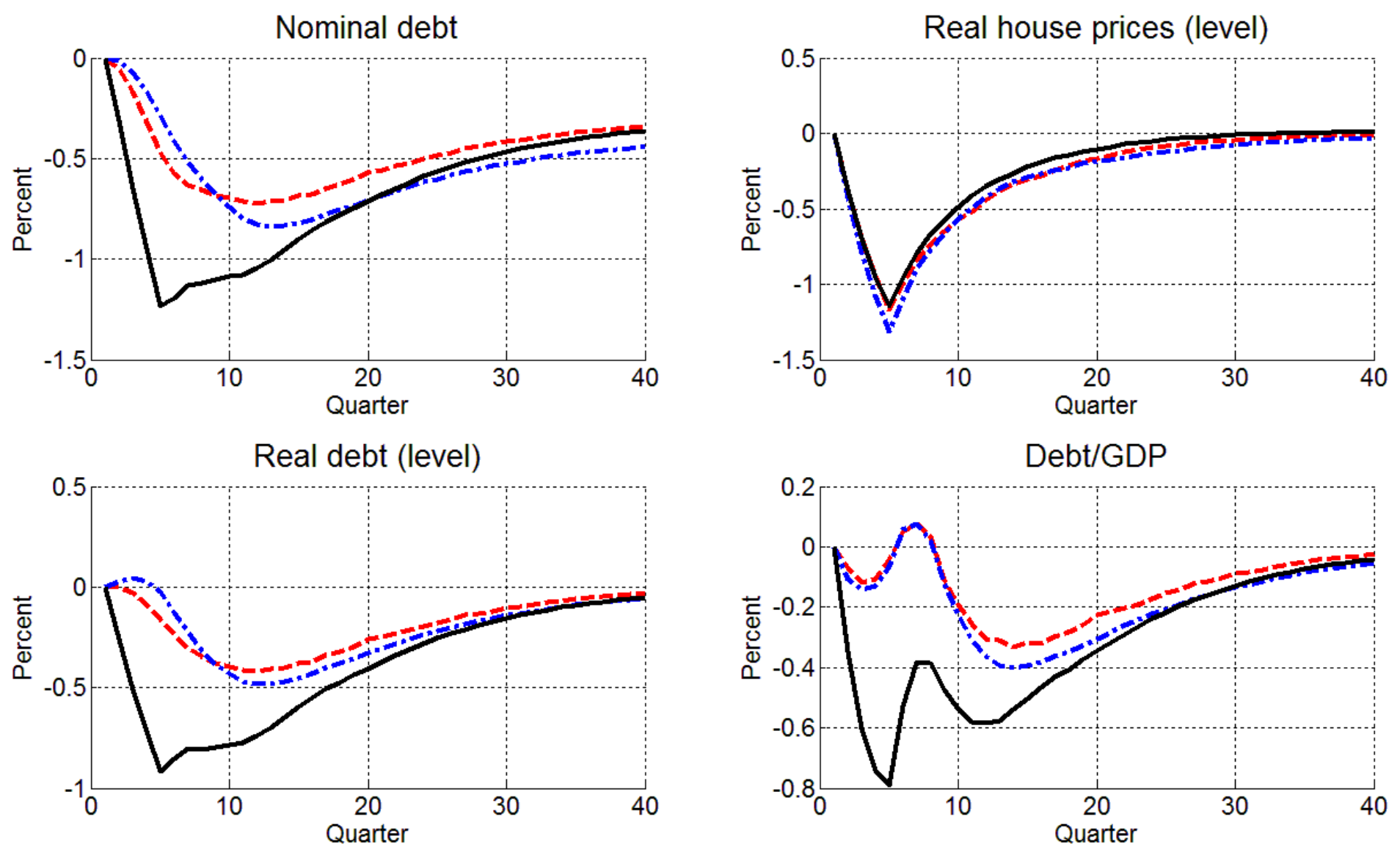

Note: The monetary policy responses are for the BVAR model with debt data (black), the BVAR with debt data where the coefficients on the repo rate (lag 1 to 4 ) in the equation for real debt are calibrated to zero (red) and the BVAR with simulated debt data ( $T=15$, blue). The responses are standardized such that the repo rate is one percentage point above baseline for a year. 
Figure A1. Total household financial debt, loans to Swedish households, and mortgage debt. Million SEK.

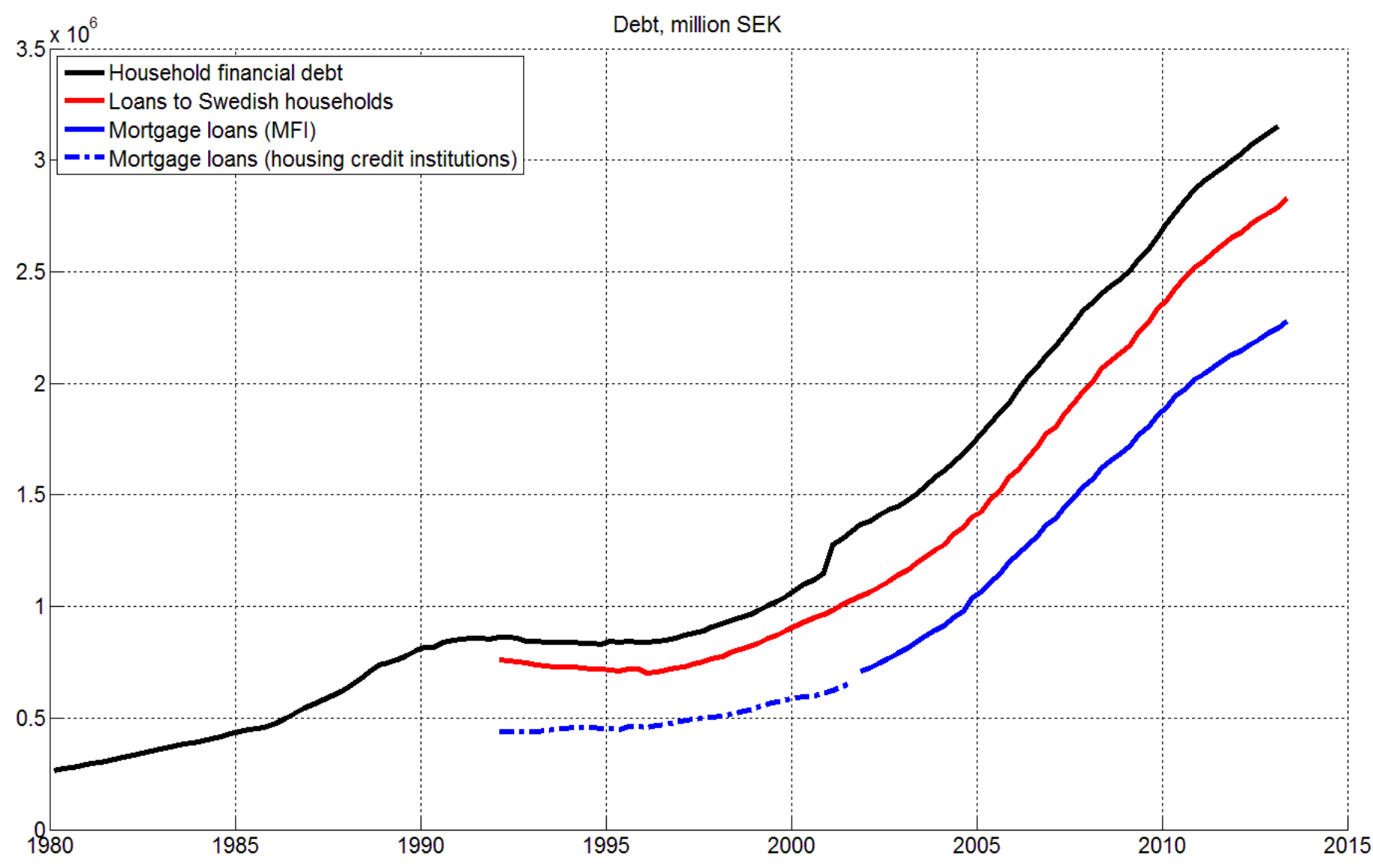

Source: Statistics Sweden 
Figure A2. Total household financial debt, loans to Swedish households, and mortgage debt. Quarterly growth rate in percent.

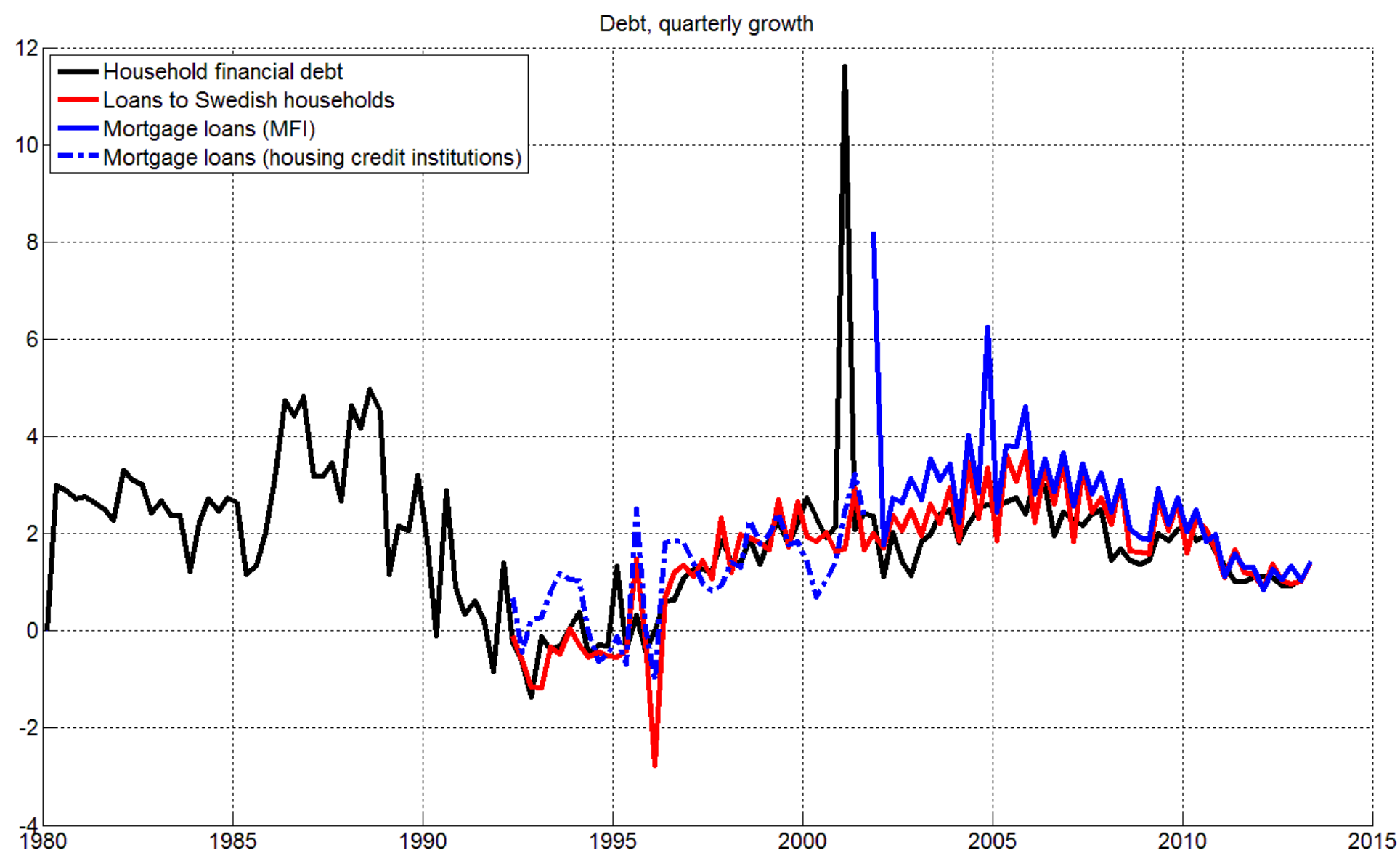

Source: Statistics Sweden 